\title{
FLORESTAN FERNANDES: UM INTELECTUAL DA EDUCAÇÃO
}

\author{
José Luís Sanfelice ${ }^{1}$
}

\begin{abstract}
RESUMO
Florestan Fernandes (1920 - 1995) foi um professor, cientista e político dentre os intelectuais mais expressivos do Brasil. Apresento aqui uma síntese da sua biografia, assinalo aspectos de sua formação, o seu engajamento na campanha em defesa da escola publica, a inserção nos debates sobre a reforma universitária e a luta travada contra o regime civil-militar instaurado após 1964, que lhe rendeu a aposentadoria compulsória. Destaco o militante que dedicou boa parte das suas ações ás questões educacionais, com grande coerência de propósito. Marx teria sido o pensador com o qual Florestan Fernandes mais se identificou. Eleito para o congresso constituinte dedicou-se à luta pela educação publica popular, á elaboração do capitulo da educação na constituição e, em seguida, a todo o processo de elaboração da nova lei de diretrizes e bases da educação nacional (LDB). Concomitantemente, foi sempre um publicista da causa educativa. Finalizo o texto com extratos de correspondências que são auto- explicativas, localizando o leitor no momento histórico e no lugar em que vivia o autor, revelando o estado de animo no qual se encontrava e as questões candentes que o afligiam. A pesquisa é de natureza bibliográfica e sua exposição visa convidar o publico para que revisitemos, todos nós, a imensa obra de Florestan Fernandes. Só teremos a ganhar intelectualmente.

Palavras-chave: Florestan Fernandes; escola pública; resistência intelectual; Marxistas brasileiros; ditadura civil-militar (1964).
\end{abstract}

\section{FLORESTAN FERNANDES: AN INTELLECTUAL OF EDUCATION}

\begin{abstract}
Florestan Fernandes $(1920$ - 1995) was a professor, scientist and politician, among the most expressive intellectuals of Brazil. I here present a summary of his biography, highlight aspects of his education, his engagement in the campaign in defense of public school, the insertion in debates about the university reform and the fight fought against the civil-military regime established after 1964, which rendered him his compulsory retirement. I emphasize the militant which dedicated a fair amount of his actions to educational questions, with high purpose coherence. Marx would have been the thinker that Florestan Fernandes most identified with. Elected to the constituent congress, he dedicated himself to the fight for popular public education, to the elaboration of the education chapter in the constitution and, after that, to the entire process of elaboration of the new law of guidelines and national education bases (LDB). Concomitantly, he was always a publicist of the educative cause. I finalize my text with extracts from correspondence that are self-explanatory, locating the reader in the historical moment and place that the author lived, revealing the state of mind in which the prominent questions that afflicted him were found. The research is of bibliographical nature and its exposure aims at inviting the public so that we revisit, all of us, Florestan Fernandes's immense work. We can only win intellectually.
\end{abstract}

Key words: Florestan Fernandes; public school; intellectual resistance; Brazilian Marxists; civil-military dictatorship (1964). 
A oportunidade que me é concedida, de participar da mesa redonda intitulada: "Os intelectuais e a educação: história e historiografia", acabou provocando a necessidade de fazer alguma escolha. No princípio surgiu a tentação de buscar uma abordagem puramente teórica do tema, mas como a $\mathrm{X}$ Jornada Nacional do HISTEDBR foi denominada de "História da Educação: intelectuais, memória e política", minha decisão final foi eleger e apresentar um intelectual que considero da maior relevância para a História da Educação brasileira. Estou me referindo ao professor, cientista e político Florestan Fernandes. Espero que ao longo das minhas considerações se justifique a escolha.

Começo, então, a apresentação com uma síntese biográfica extraída do verbete FERNANDES, Florestan que faz parte do Dicionário Histórico-Biográfico Brasileiro DHBB e de autoria de Libania Xavier (www.fgv.br/CPDOC - Acesso em 21/07/2011). Por se tratar de uma síntese, não estou em busca da originalidade.

Florestan Fernandes nasceu em 22 de julho de 1920, em São Paulo. Começou a trabalhar aos seis anos de idade como ajudante de barbeiro, engraxate e mais tarde num açougue, depois numa marcenaria e em diversos locais - alfaiataria, padaria, restaurante e bar. Após ter completado 17 anos se matriculou num curso de madureza e, de 1938 a 1940 concluiu o equivalente a sete anos de estudos. Prestou o serviço militar e aprendeu datilografia. Trabalhou em botequim, como entregador de amostras de material dentário e passou a chefe da seção de dentes, acabando por transferir-se para a área de artigos dentários. Em 1941 ingressou na Faculdade de Filosofia, Ciências e Letras, da Universidade de São Paulo (USP).

Com ajuda de custo e comissões recebidas pela venda de artigos dentários, frequentou a faculdade. Três fontes fundamentais serviram de matrizes científicas para sua formação acadêmica: a sociologia clássica e moderna, a corrente crítica do pensamento brasileiro e o pensamento marxista. Em 1943 bacharelou-se em ciências sociais, completando a licenciatura no ano seguinte.

Em 1944 e 1945 frequentou pós-graduação em sociologia e antropologia na Escola Livre de Sociologia e Política (ELSP) de São Paulo e, a partir de 1945 atuou como pesquisador e professor da Faculdade de Filosofia, Ciências e Letras da USP, ocupando o cargo de segundo assistente da cadeira de Sociologia II, cujo titular era Fernando de Azevedo. Traduziu A crítica da economia política, de Karl Marx, publicada em 1943 com prefácio dele próprio. Em 1947 obteve o título de mestre em ciências sociais, com um trabalho sobre a organização social dos Tupinambá, consagrado em 1948, ao obter o Prêmio Fábio Prado.

Em 1951 obteve o título de doutor em sociologia pela Faculdade de Filosofia, Ciências e Letras da USP. Tornou-se livre docente em 1953 e foi elevado à categoria de professor contratado em 1954. Desenvolveu pesquisa que desmentiu a tese sobre a inexistência de preconceito e discriminação no Brasil inovando a prática sociológica.

Desfez o mito que vigorava no país uma democracia social. A partir de 1959, participando da Campanha em Defesa da Escola Pública, movimento organizado para promover o projeto de lei original de Diretrizes e Bases da Educação nacional e combater o substitutivo encaminhado pelo deputado carioca Carlos Lacerda, Florestan proferiu conferências em diversos estados, aplicando análise e interpretação sociológicas à elaboração e à apresentação de diagnósticos sobre a situação educacional do país, avaliando seus limites, potencialidades e necessidades, ao mesmo tempo em que esclarecia os efeitos nefastos da alternativa de Lacerda, que beneficiava a escola 
particular em detrimento da educação pública. Em 1964 tornou-se catedrático em sociologia I. Preso por ocasião do movimento civil-militar de 1964, não ficou muito tempo na cadeia devido à grande repercussão alcançada pela carta aberta que fez publicar na imprensa, afirmando que 'se a grande virtude do militar era a disciplina, a do intelectual era o espírito crítico'. Nos anos subsequentes utilizou os instrumentos da sociologia para denunciar e lutar contra o regime militar. A publicação de Educação $e$ sociedade no Brasil, em 1966, reuniu estudos do autor sobre questões educacionais produzidas entre 1946 e 1962. Incorporando o marxismo do ponto de vista sociológico, o professor exerceu ampla repercussão na formação das gerações de sociólogos que saíram da USP na década de 1960.

Sua militância em prol da educação brasileira prosseguiu com o processo de discussões em torno da reforma universitária. Conferências e entrevistas desta época culminaram no texto intitulado Os dilemas da reforma universitária consentida. Submetido a inquérito policial militar, processado, julgado e afinal declarado inocente pela Justiça Militar, não obstante Florestan Fernandes foi afastado da USP em 1969 e aposentado pelo Ato Institucional $\mathrm{n}^{\circ} 5$ (AI-5). Em novembro, transferindo-se para os Estados Unidos, Florestan atuou como professor visitante na Universidade de Colúmbia e, posteriormente, lecionou na Universidade de Toronto, até 1972. Vinculado à Universidade de Yale de 1975 a 1978, retornou ao Brasil para tornar-se professor da Pontifícia Universidade Católica de São Paulo. Simpatizante e contribuinte do Partido dos Trabalhadores (PT) desde a sua fundação em 1980, publicou a partir de outubro diversos artigos na Folha de São Paulo. Em 1986, a convite do presidente nacional do PT, Luís Inácio Lula da Silva, filiou-se à agremiação. A questão da USP, lançado por ocasião do centenário da universidade, inscreve-se no contexto da militância do autor em prol da educação pública. Em novembro de 1986 elegeu-se deputado federal constituinte pela legenda do PT. Na fase de elaboração complementar da Constituição, coube a Florestan coordenar a ação do PT nas áreas educacional e cultural. Posteriormente à promulgação da nova Carta, participou ativamente do processo de elaboração, discussão e aprovação da Lei de Diretrizes e Bases da Educação Nacional, iniciado em dezembro de 1988. O desafio educacional (1989) reúne artigos publicados em jornais e revistas, entrevistas, textos de conferências e ensaios sobre a questão educacional dos anos 1980. Reeleito em outubro de 1990, iniciou o novo mandato em fevereiro de 1991. Ao longo das décadas de 1980 e 1990, Florestan publicou vários livros centrados na conjuntura política, entre os quais LDB: impasses e contradições (1993) e Tensões da educação (1995). De junho de 1989 a agosto de 1995 manteve uma coluna semanal regular na Folha de São Paulo. O seu falecimento ocorreu em São Paulo em 10 de agosto de 1995.

Com essa síntese espero ter trazido um rápido perfil do intelectual militante que dedicou grande parte das suas ações às questões educacionais em alguns dos seus momentos bastante cruciais: na tramitação do projeto da primeira LDB; na Campanha em Defesa da Escola Pública; na Reforma universitária da ditadura civil-militar de 1964; na elaboração da última Constituição e na construção da nova LDB. Ficaram aqui esmaecidas as atividades do docente e sociólogo, mas foi intencional.

Um artigo de Saviani (1996) permite diminuir as lacunas acima. Ele considera, por exemplo, que as preocupações educacionais de Florestan Fernandes estiveram presentes em todas as suas ações e aborda quatro facetas em destaque: a docência, a pesquisa, a militância e a publicísta tomadas como indissociáveis e resultantes de 
grande coerência de propósitos. Marx teria sido o pensador com o qual Florestan Fernandes mais se identificou.

\section{$\underline{\text { O Professor-educador }}$}

[[...]] em lugar de se constituir simplesmente como um professor - sem dúvida sério, consistente e responsável, ministrando um ensino de qualidade a sucessivas turmas de alunos conforme a expectativa social e institucional estabelecida - foi levado a converter a cadeira de Sociologia I da Faculdade de Filosofia, Ciências e Letras da USP, que ficou sob sua responsabilidade a partir de 1952-53, num verdadeiro espaço educativo destinado a formar quadros de alto nível no campo das ciências sociais (SAVIANI, 1996, p. 72, grifos meus)

Fiz os grifos na citação paria ressaltar que Saviani buscou demonstrar o quanto Florestan Fernandes foi ambas as coisas, ou seja, professor-educador. Pondera Saviani, com base nos escritos de Florestan Fernandes que mesmo não sendo um pedagogo ou cientista da educação, no sentido especializado dessas expressões, que "a partir da experiência de sua própria formação e do processo formativo que passou a liderar como professor", isso o levou "a atuar como um verdadeiro educador, isto é, aquele que pratica a educação com a consciência clara de que a está praticando, o que o leva a formular conceitos de máxima significação para o conhecimento da essência própria dos fenômenos educativos" (Ibid: 72).

\section{$\underline{O \text { cientista e a educação }}$}

Mergulhando nos escritos de Florestan Fernandes, Saviani considera que ele evidenciou as esperanças que depositava na educação e sempre com a preocupação de demonstrar como os cientistas sociais deveriam encarar a sua participação e responsabilidade nos projetos de reconstrução do sistema educacional brasileiro, num processo de cooperação com os educadores. Sobressai à obra

[[...]] a figura do sociólogo crítico e militante, que encara a educação seja como objeto de análise científica seja como campo de intervenção prática, ambos os aspectos requerendo, de forma articulada, a contribuição do sociólogo[[...]] (Ibid.: 78).

\section{$\underline{\text { O militante da educação pública }}$}

Saviani considera a militância de Florestan Fernandes desde os anos quarenta do século XX ainda como estudante e depois como professor universitário. São suas ações políticas, suas publicações na imprensa e outras atividades que a comprovam.

Entretanto, é com a 'Campanha em Defesa da Escola Pública' desencadeada em 1959 em torno da discussão e aprovação do Projeto de Lei de Diretrizes e Bases da Educação Nacional, que sua condição de 
militante da educação pública aflora plenamente projetando-se por todo o país. Com efeito Florestan Fernandes constituiu a liderança mais expressiva e combativa do movimento em defesa da escola pública naquele período (Ibid.: 79).

Mas não foi só isso. Florestan Fernandes ainda faria expressivas intervenções na questão da reforma universitária nos anos de 1964 a 1969 quando proferiu conferências e contribuiu com textos analíticos que resultaram em novas publicações; participando do centenário da Universidade de São Paulo e, a partir, de 1986, quando foi eleito para o Congresso Constituinte, se dedicou à luta pela educação pública popular, à elaboração do capítulo da educação na Constituição e, na sequência, a todo o processo de elaboração da nova LDB (Ibid.: 81-82).

\section{$\underline{O}$ publicista da causa educativa}

Florestan, ao longo de sua trajetória, frequentou assiduamente a imprensa escrita, divulgando incansavelmente um saber crítico da sociedade encarado como instrumento para a necessária ação transformadora a ser protagonizada pelos de baixo (Ibid.: 82).

Saviani identifica em Florestan um sentido crítico e revolucionário no trato das funções da universidade: a pesquisa, o ensino e a extensão, bem como uma postura gramsciana que reivindica a difusão crítica das verdades já descobertas, socializandoas.

B. Freitag (2005) compara Florestan Fernandes aos intelectuais da estirpe de Heinrich Heine, J. P. Sartre, Jürgen Habermas e outros equivalentes. Lembra que seus professores na USP foram Roger Bastide, Emilio Willems, Radcliffe-Brown e Donald Pierson. E, para demonstrar a coerência do intelectual aponta que ele não trabalhou para o Cebrap que havia sido fundado com recursos da Fundação Ford uma vez que "atribuía aos EUA a iniciativa de iniciar e sustentar o golpe militar no Brasil". E, quando do seu ingresso no Partido dos Trabalhadores, só o fez com a certeza de que o partido não o financiaria, mas o sociólogo financiaria o partido.

A autora acima citada fez sua dissertação de mestrado (1965-1967) e a defendeu no Departamento de Ciências Sociais da Freie Universität Berlin . Seu trabalho foi de comparação das obras de Gilberto Freire, Florestan Fernandes e Celso Furtado, "focalizando suas concepções sobre o passado, o presente e o futuro do desenvolvimento socioeconômico brasileiro" (Ibid.: 233).

Em relação a Florestan Fernandes, B. Freitag destaca a leitura que ele fez da primeira metade do século XX destacando as contradições e os dilemas presentes: $\mathrm{o}$ dilema social, o dilema racial e o dilema educacional.

Esses três dilemas explicariam porque na sociedade brasileira da primeira metade do século XX, aparentemente não há nem conflito nem discriminação racial. Em verdade, existe uma sobreposição de classe e raça, em que as diferenças e injustiças socioeconômicas encobrem o conflito racial. Os pobres são, em sua maioria, negros ou mestiços. A pobreza ofusca a raça. Nas escolas (mesmo públicas) e universidades, os 
negros e mestiços estão sub-representados, reservando-se a maior parte das vagas para os brancos.

[[...]] Fernandes não esconde sua simpatia e solidariedade incondicionais pelos oprimidos, excluídos, desprivilegiados. Longe de estar 'desprendido' de sua origem social ([[...]]), Fernandes usa-a como arma para denunciar o cinismo e a ideologia de uma sociedade hipócrita que se diz democrática mas que, em verdade, acumula privilégios para minorias tradicionalmente beneficiadas, reforçando injustiças, cristalizadas em uma das concentrações de renda mais elevadas do mundo (Ibid.: 235).

B. Freitag revela que na conclusão da sua dissertação de mestrado deparou-se com um paradoxo: F. Fernandes havia recorrido a uma sociologia positivista, mas era um cientista social crítico e engajado, sem a neutralidade pretendida pelo positivismo e, capaz de defender uma causa política como, por exemplo, na Campanha em Defesa da Escola Pública. A autora entende que sua dissertação parecia "confirmar a tese marxista de que nossa Weltanschauung (visão de mundo) é reflexo das condições materiais em que vivemos. Das Sein bestimmt das Bewussstsein, ou seja, 'o ser determina a consciência"” (Ibid.: 236). E, isso explicaria o paradoxo.

Vinte anos após ter concluído a sua dissertação de mestrado B. Freitag participou da Jornada Florestan Fernandes realizada na UNESP - campus de Marília SP em 1986. Discursou sobre o sociólogo no bloco dedicado à questão da 'Universidade e Democracia' debatendo o tema 'Democratização, Universidade, Revolução'. Na ocasião, analisando então obras mais recentes de F. Fernandes, defendeu a tese de que havia ocorrido uma ruptura epistemológica na produção do sociólogo.

\begin{abstract}
Argumentei que a produção intelectual de Fernandes sofre, na virada da década de 1960 para 1970, uma profunda re-orientação. A fim de pontuar essa mudança, batizei a sua obra de antes da ruptura como sua fase 'acadêmico-reformista' e seu período posterior ao AI-5 como 'políticorevolucionária’ [[...]] (Ibid.: 236).
\end{abstract}

Para a autora, na primeira fase aparecia um F. Fernandes com um conceitual teórico baseado em Durkheim, Weber, Mannheim, Freyer e Radcliffe-Brown, com uma metodologia funcionalista, privilegiando a reflexão sobre a Sociologia como disciplina, a análise antropológica do índio brasileiro e o estudo pormenorizado da realidade brasileira.

$\mathrm{Na}$ segunda fase surge um F. Fernandes alicerçado por um referencial teórico buscado nos conceitos de Marx, Engels e Lenine, no método do materialismo histórico e em outros marxistas. A temática que se destaca agora é a guerrilha urbana, a revolução cubana e a ditadura militar brasileira. Antes F. Fernandes via na educação, na ciência e na universidade um potencial decisivo para a transformação da sociedade brasileira. Em seguida passa a argumentar em prol da ação revolucionária na sociedade como um todo para também revolucionar a educação.

Finalmente B. Freitag faz algumas ressalvas sobre a questão da ruptura epistemológica que F. Fernandes teria vivenciado, dizendo que no sociólogo reformista já se encontrava o embrião do revolucionário. Considera ainda que F. Fernandes assumiu uma terceira fase em sua vida como membro do Partido dos Trabalhadores e da Assembléia Constituinte, período em que não mais voltou a trabalhar numa 
instituição de ensino superior. "Em conversas e cartas exprimia seu desprezo pela burocratização da universidade e pelo carreirismo egocêntrico da maioria dos professores e pesquisadores, que repassavam essas atitudes às novas gerações de universitários" (Ibid.: 241). E, destaca ainda que, como articulista da Folha de São Paulo, ele não procurava somente formar opiniões e consciência política, mas 'educar' o seu leitor, pois via no jornalismo um instrumento mais eficaz do que o professor em sala de aula. "Ele foi simplesmente um dos maiores intelectuais que o Brasil conheceu até agora" (Ibid.: 242).

Embora dez anos antes de produzir o artigo acima B. Freitag já tivesse publicado um texto que denominou Florestan Fernandes por ele mesmo, preferi romper com a ordem cronológica para ressaltar a fala do próprio Florestan, agora. A correspondência entre eles é referente a um período de quase trinta anos: 1966-1994. B. Freitag explica as condições sob as quais ocorreu a troca de missivas, os critérios de que se utilizou para selecioná-las e considera: "O teor das cartas é auto-explicativo, dispensando a caracterização do contexto em que foram escritas. Florestan Fernandes encarrega-se, ele próprio de situar o leitor no momento histórico, no lugar em que vive, revelando o estado de ânimo no qual se encontra [[...]] eu não hesitaria em socializar essas cartas no devido momento, pois o autor que vive nelas pertence a todos" (B. Freitag, 1996).

Da minha parte, farei uma brevíssima indicação de trechos que não são para matar a curiosidade do leitor mas, para acrescentar alguns elementos ao que já foi dito sobre o sociólogo.

De S. Paulo, 3-8-66

Durante minha estadia nos Estados Unidos, escrevi um trabalho que interessaria muito, sobre 'A dinâmica da mudança sócio-cultural no Brasil'. Dele foi publicada em 1965 uma edição mimeografada, em inglês, pela Universidade de Columbia [[...]] Em português, o trabalho foi publicado pelos Cadernos Brasileiros [[...]] Para uma reunião sobre ciências sociais, realizada sob o patrocínio do The Social Science Research Council, apresentei um trabalho de interesse para os seus propósitos; e, ainda agora, escrevi um ensaio de 39 p. sobre crescimento econômico e instabilidade política no Brasil, para os colóquios que se realizarão no próximo mês em Harvard[[...]]

De S. Paulo, 1.2.67

Quanto aos dados biográficos, não sei o que dizer. Os dados que já mandei não são suficientes. Seria melhor, no caso de precisar alguma informação, de pedi-las especificamente. Nasci em 22.7.1920; sou casado, tenho 6 filhos e uma neta; quanto aos livros, as teses e os diplomas, já mandei dados a você. Se tiver ocasião (dependendo do trabalho de minha secretaria), procurarei atualizar um curriculum meu. Todavia não posso prometer nada, porque isso exigiria algum tempo e é provável que eu não disponha dele, neste período do ano e com os acontecimentos que estamos enfrentando na esfera da reforma universitária (grifo meu). 
Em longos parágrafos F. Fernandes explica para B. Freitag as influências intelectuais que recebeu e como reagiu seletivamente a elas. A influência francesa na sociologia, na política, na economia e na filosofia; a influência alemã na etnologia e na sociologia; a influência norte-americana na sociologia e, com menos intensidade, a influência italiana na estatística. Tudo por conta da presença de inúmeros professores estrangeiros na Universidade de São Paulo.

[[...]] impus-me o dever de conhecer tão profundamente quanto possível as diferentes tendências da sociologia, dos precursores aos modernos e atuais $[[\ldots]]$; aprendi as técnicas de investigação empírica mais exploradas nos Estados Unidos [[...]]; valorizei muito a ligação entre teoria e pesquisa empírica sistemática. Por fim, graças à ligação com o marxismo, me interessei deveras pela sistematização teórica da sociologia aplicada. [[...]] fui além de Mannheim que nunca conseguiu superar o impasse do pensamento liberal [[...]]

Acho que consegui algum êxito: nos alvos relacionados com a pesquisa empírica (imprimi o rigor possível à pesquisa da reconstrução histórica [[...]]; e pude encadear pesquisa histórica e pesquisa de campo de modo mais amplo e preciso [[...] No ensino, sempre procurei evitar um dogmatismo prematuro. Sempre preferi orientar os meus estudantes de uma forma ampla, mais informando-os e preparando-os para fazer escolhas, do que escolhendo por eles próprios. Doutro lado, procurei instiga-los a partir das pesquisas, por julgar deformadora a antiga via 'filosófica', que dava preeminência, ao domínio de idéias gerais, mas esquecia que o cientista se forma trabalhando objetivamente sobre dados de fato, ainda que com propósitos lógicos de explicação da realidade (Ibid.: 1996, grifos meus).

F. Fernandes ainda faz referências às condições precárias do trabalhador da pesquisa no Brasil que isolado ou em pequenos grupos tem que se dedicar a um "faz tudo". Lamenta-se das dificuldades que o sociólogo tem de se comunicar com os leigos letrados por conta da insuficiente secularização da cultura e arrola dezenas de livros e autores alemães, franceses, ingleses, italianos e dos Estados Unidos que foram objeto de seus meticulosos estudos

"Seria difícil dizer quais foram as influências principais. Por ordem, de magnitude, poria em primeiro plano e com grandeza análoga Durkheim, Marx e Mannheim [[...]] Doutro lado, seria bom ressaltar que sempre valorizei o conhecimento das ciências afins, procurando informar-me quanto ao desenvolvimento da antropologia, da economia, da psicologia social e da política" (Ibid.: 1996, grifos meus).

De São Paulo: 6.4.67

Os cientistas sociais, pelo menos os melhores, avançaram bastante para vencerem as limitações da velha tradição acadêmica. Acabaram como eu e Celso Furtado: ele com os direitos políticos cassados e eu preso e tendo de bater nas portas da justiça para defender a liberdade de pensamento e a dignidade intelectual do investigador (Ibid.: 1996). 
De São Paulo: 4.11. 68

Infelizmente a minha vida anda numa barafunda. Não é tanto desorganizada; eu é que não tenho mais controle do tempo. Muitas conferências, como dizem os estudantes - para 'conscientizar' e lá vai o meu tempo. Como se trata de uma forma de luta, acedi [[...]]

A nossa escola foi bombardeada: pelos 'alunos' do Mackenzie, ou melhor, pelo CCC (comando de caça comunista). Em um dia o conflito foi localizado; no dia seguinte, os jovens da extrema direita atacaram rijo, com a polícia espiando e apoiando como se a faculdade fosse um parque de tiro ao alvo. Destruiram tanta coisa, de cortar o coração. Fiquei furioso. Mas, nada pude fazer - nem posso nem poderei. $\mathrm{O}$ remédio não está em responder ódio com ódio. Mas, em corrigir a sociedade brasileira. O que é difícil. Para mim a violência é um recurso político: só deve ser usada para atingir certos fins quando não existem outros meios e existem probabilidades de mudança da situação. A luta atual está entre o meio fascismo (o fascismo disfarçado existente) e o fascismo declarado, que a extrema direita quer impor ao País. É difícil ter êxito político em tal contexto, principalmente porque a violência faz parte da opressão organizada, manipulada a partir de cima pelas classes no poder.

Estou preparando um novo livro. Reúne algumas conferências [...] que pronunciei no decorrer da campanha que fiz em prol da reforma universitária que deverá ser também uma reconstrução da sociedade: $\mathrm{R}$. U. quer dizer, para nós, construção de uma sociedade democrática (Ibid.: 1996, grifos meus).

De São Paulo: 24.2.69

Quanto a mim, fiquei surpreso com o diagnóstico: não pertenço apenas teoricamente mas também praticamente à esquerda. Só não participo de um partido, porque não existe; e, por formação universitária, só poderia ser um marxista na tradição europeia, isto é, democrática e heterodoxa [...] coloquei em primeiro plano a solução dos problemas, nunca me manifestei, de modo sistemático, como 'socialista'; preferi fazê-lo numa posição que acarreta os seus equívocos: a do 'sociólogo participante', empenhado nos processos de democratização das estruturas sociais, econômicas e políticas do seu País (Ibid.: 1996).

De São Paulo, 2.6.69

[...] eu e outros professores da USP (e de outras escolas) fomos aposentados compulsoriamente pelo Governo Estadual (grifo no original). Trata-se de uma medida que esperava desde 20 de dezembro do ano passado. Os seus resultados nefastos: perda súbita de parte substancial da renda; necessidade de acumular alguns trabalhos remunerados de natureza intelectual; premência de sair do Brasil (pois o artigo $3^{\circ}$ do ato institucional $\mathrm{n}^{\circ} 10$ fecha-nos as portas do ensino, da pesquisa e da tecnologia, ao alvitre das autoridades).(Ibid.: 1996). 
De Toronto, 22.4.70

O homem é limitado por sua condição humana. Não vou mais longe que os outros e talvez tenha certas limitações incuráveis, que nascem de cicatrizes do passado. São as cicatrizes que me tornam um tanto relutante para aproveitar as vantagens que minha posição me proporciona (como o caso da dotação oferecida pela Fundação Volkswagen, com a qual vou fazer o mesmo que já fiz com ofertas análogas da Fundação Ford), e que percebo me levam a agir de forma irracional. Um paradoxo. Tentar ser 'racional' por vias irracionais. O que fala, porém, é o meu passado, tão vivo em minha consciência crítica, de criança que começou a enfrentar a vida em toda a plenitude do meu passado, não posso ser mais que uma aberração no mundo em que vivemos, no qual as criaturas se 'valorizam' através do mercado (como diria o circunspecto Max Weber) e trocam o hoje pelo amanhã e o amanhã pelo depois do amanhã. A fonte de minha força não passa, portanto, de uma mesma fraqueza, já que estou condenado a ser um mero intelectual. [...] O círculo se fecha, vim para cá pensando em um ano. Andei considerando convites para passar tempo. Porém, agora vejo que tenho de mudar meus planos. (Ibid.: 1996).

De Toronto, 1.12.70

[...] Numa fase em que ando no fundo do poço - cansado do meu trabalho, cansado de ser professor e até cansado da comida, da cidade e do tipo de vida que levo em Toronto. Acho que atingi o limite da saturação.

Ainda por cima, as notícias que vem do Brasil sempre ajudam a afundar o poço [...] Para terminar tudo vem a notícia ([...]) de que a polícia foi duas vezes à minha casa para me prender. Não é cabo de esquadra? De emprego que é bom nem ouço falar. Minhas cartas, por enquanto (há quase 3 meses) estão aguardando resposta. Como diz o ditado brasileiro: em tempo de murici, cada um cuida de si (grifo no original).

Continuo com ânimo. Enquanto se vive, se luta ou então não se entrega a rapadura. (Acho que estou em verve folclórica, pois repeti outro provérbio). Todavia, torna-se cada vez mais difícil para mim estabelecer uma ponte entre o que sou e o que faço e o que desejaria ser e fazer. Não tenho pena do Florestan, velho e calejado; mas às vezes olho para mim mesmo com certa ironia, pois me especializei em dar murros em ponta de faca e agora que me vejo lançado realmente no mercado, como mercadoria estimada em dólares, sinto que as minhas técnicas estão superadas e que seria melhor vender sorvetes numa rua quente de São Paulo do que ser professor de sociologia no Norte das Américas.

[...] Quanto ao desejo de voltar ao Brasil, já nem é mais coragem. É parte de uma mecânica, em que a vida obriga e em que o eu cede. Quero muito voltar. Mas, mesmo que não o quisesse, teria de fazê-lo. Vamos ver se as chamadas 'condições externas' não cortam essa necessidade, ao mesmo tempo objetiva e subjetiva, pela essência dialética. (Ibid.: 1996)

De Toronto, 29.1.71

A 'ciência' está injetando na Europa a mesma dose de pusilanimidade, de co-optation e de conformismo deliberado (embora também bem disfarçado) que já instilou nos Estados Unidos. Hoje, aprende-se mais 
lendo um bom artigo de orientação crítica - quando os jornalistas fazem uma descrição 'honesta' - ou um romance, do que se lendo obras de cientistas políticos, sociólogos e economistas de 'alto nível'. Fico cada vez mais revoltado com esse 'alto nível', os 'modelos' sofisticados e o vazio total que eles envolvem, uma ciência útil para quem comanda burocraticamente e pode pagar um 'preço funcional' pelas decisões impostas de cima para baixo[...]

Eu estava engajado numa merda de uma política pequeno-burguesa, na qual os pressupostos do jogo político consistiam em nossa fraqueza. Um punhado de intelectuais, de estudantes, de líderes sindicais e políticos de esquerda, tentando enfrentar a avalanche da fome católica pelo controle das consciências e dos setores conservadores pela destruição da escola pública independente. Naquela situação, recorri a um equivalente da simulação: os pressupostos ideais do Estado democrático. Uma maneira de fazer a 'crítica moral', que desarma os inimigos e cria aliados, por ser irretorquível. Funda-se nos dados e nas exigências do 'sistema'. Se ele existe, logo tem de manter-se e de aperfeiçoar-se. Nesse quadro, no qual imergia como uma putaine respectuese e com dor de cornos (tendo de falar ao público reiteradamente - o que as vezes não consta dos escritos que aquilo não correspondia aos valores da minha posição pessoal, socialista), o argumento era por essência político e visava fazer aliados. $\mathrm{O}$ que consegui (e outros junto comigo). Uma boa parte dos 'liberais' de várias gamas saíram do convento e se puseram na liça (inclusive os atuais arautos da Revolução, educadores como Laerte Ramos de Carvalho, roque Spencer Maciel de Barros, Carlos Correa Mascaro e tantos outros). (Ibid.: 1996).

De São Paulo, 21.7.75

A sua pergunta a respeito do que ando escrevendo. Não estou escrevendo nada e também não sinto vontade de escrever. Depois de escrever tanto ando de maré baixa e não sei quando retomarei o antigo entusiasmo. Leio muito, mas sem método, como se fosse um adolescente desorientado. Também, falta-me um objetivo central. Os livros correm-me pelas mãos e, aqui ou ali, fixo-me em um, e leio-o de cabo a rabo. (Ibid.; 1996);

De São Paulo, 19.3.76

[...] andei um pouco fora dos trilhos e, como sucede comigo, lendo e escrevendo à la neurótico [...]

Estou um pouco saturado de tudo isto e de uma luta sem fim que não conduz a nada, como se eu fosse uma reedição empobrecida do herói mais quixotesco da pobre cena histórica latino-americana e brasileira. Nem me resta dizer: fiz o que pude. O que se deve fazer depois disso? Não pense que se trata de pessimismo. Acho que transcendi aos quadros de uma situação que foi devorada pela condição periférica do intelectual brasileiro. A sociologia crítica pode servir para a pose de alguns felizardos europeus e norte-americanos. Para nós ela não é nem o sucedâneo de um envelope de cafeaspirina [...]

Mas a história tem os seus ritmos e a sua direção; pior para os lúcidos ou para os honestos ou para os inquietos e pior ainda para os que são tudo isso de uma vez [...] que a Adriana consiga viver em uma sociedade socialista, porque não acho que alguém possa ter 'paz e amor' ou 
felicidade no sentido autêntico da palavra dentro do mundo criado pela 'civilização industrial capitalista' (Ibid.: 1996, grifos meus).

De New Haven, 22.3.77

Não posso dizer uma coisa e fazer outra. Seria muito fácil - o que não está no meu gênero. Além do mais, acho que o meu ciclo institucional está encerrado. Poderei fazer algo aqui ou ali, mas retomar o trabalho acadêmico intensivo e cerrado não me atrai mais. $\mathrm{O}$ rato que escapuliu, da ratoeira não volta a ela, mesmo que seja atraído pelo melhor queijo do mundo. Imagine um homem. Por que deveria?

[...] E a horrível sensação de que perdemos a batalha, apesar de termos pelo menos alguns entre nós - feito o possível para vencê-la. Isso contudo importa pouco. A guerra continua. Enquanto existir capitalismo nada pode impedir essa realidade (Ibid.: 1996, grifos meus).

De São Paulo, 4.11.77

O que é um intelectual de vanguarda? Nós não temos 'vanguarda', de modo que ataco como posso e tento segurar as pontas [...] Apoio mesmo só de um ralo grupinho de inocentes. Parece que os inocentes irão salvar o mundo, aqui e aí. [...] comecei a lecionar na PUC .. Poderia parecer que deveria ficar contente. Não fiquei. A minha reação é melancolia. Perdida a identidade profissional, o ensino não traz aquelas compensações maravilhosas. Gosto do contato com os jovens e eles ainda me consideram parte da grei. Todavia, já sou pão amanhecido. Há quem goste. Contudo, eu próprio não tenho ilusões. O meu momento já passou. Faço o que posso, à maneira artesanal, com consciência do 'dever' e do 'melhor possível'. A magia, porém, se quebrou há tempo e eu contentome com esse desdobramento do artesão que sempre viveu dentro de mim. Sinto muita falta do velho ambiente. Trabalhava-se, lutava-se, discutia-se, vivia-se. Hoje, como na política,, o clima é de desencanto. Não perdi a tempera, mas sinto-me como se combatesse moinhos de vento, sem ser um Quixote [...] A sociologia, por sua vez, resvalou e o socialismo continua sempre muito difícil. Eu próprio, ao que parece, compliquei o meu caminho e tenho de renascer das cinzas [...] ou levar a breca. No interim, a volta às salas de aula tem a importância de ocupar-me física e mentalmente, saturando um vazio que quase me destruiu. (Ibid.; 1996, grifos meus).

De São Paulo, 25.8.78

Consegui abrir minha coleção sobre 'Pensamento socialista' com o $\underline{\mathrm{O} \text { que }}$ fazer? de Lenin, para a qual fiz uma apresentação curta mas que está sendo muito apreciada. Além disso saiu o meu livrinho sobre Lenin, pela Ática, e foi um estouro editorial [...]

Lamentavelmente, já não gosto de dar aulas. É um sacrifício, que tenho de aceitar. Quanto à PUC nela me sinto um estranho. E não deveria sentir-me? (Ibid.: 1996). 
De São Paulo, 17.8.79

[...] Sinto-me cada vez mais distante da 'academia' (por que academia?) e a sociologia já foi. Gostaria de uma boa revolução socialista, dessas que não deixam espaço para qualquer social democracia à germânica. Isso sim. Então, sou um herege. Levo bafo de onça para o ser puritanismo sociológico. (Ibid.: 1996).

De São Paulo, 3.5.83

Lamento ser um homem desvalido - deliberadamente desvalido -, pois me desinstitucionalizei voluntariamente. Os estudantes custam a compreender e parece que não se conformam com isso [...] Há rupturas e rupturas. A minha levou ao fundo do poço, onde fiquei isolado e sem os riscos de ser salvo por uma caravana de mercadores. A cisterna é boa e posso movimentar-me e sem os constrangimentos e as violações do encurralamento institucional. Voltei á condição de humpem, de vagabundo, embora tenha mais dinheiro que em qualquer outra época de minha vida [...]

Muitos acham que desprezo a universidade e o trabalho acadêmico. Que inversão. $\underline{O}$ que desprezo é a universidade voltada sobre si mesma e o trabalho acadêmico que não tem outro fim que o da 'carreira', do 'êxito profissional' e da 'produção' para o currículo.

1964 mostrou-me que a universidade que eu tinha na cabeça nunca existirá no Brasil e que o verdadeiro campo de batalha só existe quando o intelectual pode mergulhar em movimentos que arrasam para construir, $o$ que ainda é uma miragem em nossa pobre cena política, que mais se parece com um teatro de marionetes. Por conseguinte luto como posso, na certeza que os tais movimentos virão - na verdade, se há alguma esperança, desde 1978, ela vem daí - embora seja difícil que eu próprio venha a aproveitar essa revirada liberdade da história (Ibid.: 1996, grifos meus).

De São Paulo, 24.4.94

Mas penso que um partido socialista deve restringir os número de mandatos a dois, para evitar a 'profissionalização política', com suas consequências nefastas.

Espero, com os excertos acima, ter contribuído um pouco para dimensionar a relevância de F. Fernandes naqueles aspectos ressaltados por Saviani (1996), a saber, o docente, o pesquisador, o militante e o publicista. Nas cartas do sociólogo há muita presença unitária das múltiplas facetas do seu incansável trabalho. Houve momentos de desânimos, perante grandes adversidades mas, na sequência, sempre surgiam novas esperanças e a vontade da luta renascia. Pelos excertos das cartas a humanidade de F. Fernandes se expõe. Penso ter sido uma razoável lembrança trazer a X Jornada do Histedbr "História da Educação: intelectuais, memória e política" a presente reflexão, mais do que uma singela homenagem a F. Fernandes, um convite: revisitemos todos as suas obras, só teremos a ganhar intelectualmente. 


\section{Referências}

FREITAG, B. Florestan Fernandes por ele mesmo. Estudos Avançados. vol. 10, n 26. São Paulo, jan./abr. 1996.

FREITAG, B. Florestan Fernandes: revisitado. Estudos Avançados. vol. 19, n 55. São Paulo, set./dez. 2005.

SANFELICE, J. L. O Manifesto dos Educadores (1959) à luz da história. Educação e Sociedade. vol. 28, $\mathrm{n}^{\circ}$ 99. Campinas, maio/ago. 2007.

SANFELICE, J. L. O movimento civil-militar de 1964 e os intelectuais. Cad. CEDES. vol. 28, n 76. Campinas, set./dez. 2008, pp. 357-358.

SAVIANI, D. Florestan Fernandes e a educação. Estudos Avançados. vol. 10, n 26. São Paulo, jan./abr. 1996.

XAVIER, L. Fernandes, Florestan. Verbetes do Dicionário - Biográfico Brasileiro DHBB. www.fgv.br/cpdoc. (Acesso em 21/07/2011).

Nota

${ }^{1}$ Professor Titular em História da Educação. UNICAMP/FE/DFHE. (Aposentado e colaborador). Pesquisador permanente do Grupo de Estudos e Pesquisas História, Sociedade e Educação no Brasil HISTEDBR. sanfelice00@yahoo.com.br

Recebido em Fevereiro/ 2014

Aprovado em Março/2014 